\title{
Integrated Hospital Management System
}

\author{
Maha Mohamed Ahmed Al Habsia ${ }^{a}$, Syed Ateeq Ahmed ${ }^{\mathrm{a}}$,
}

There are many private hospitals in Oman. Some of the hospitals are having their own web-based applications providing the details of services provided by the hospital and manage appointments done by the patients. However, there is no web-based application which provides a common integrated platform to compare services provided by various hospitals and manage the patient's consultations with doctors. This research paper is targeted towards integrating services provided by various private hospitals. The prime focus of this research is to design a prototype for web-based application and provide an implementation strategy in developing an integrated solution. This research is intended towards serving the community in Oman by giving the flexibility to the patients in comparing the services of various hospitals with ease and choosing the hospital of their choice by booking appointments easily from their home avoiding long waiting queues in hospitals. The proposed prototype system can also manage the patient's treatment details and track their medical history.

Keywords: Integrated hospital management system (IHMS), Entity-relationship (ER) diagram, normalization

\section{Introduction}

In the last few years, several hospitals in Muscat, Oman have started providing web-based services for the patients to choose the services provided in the hospital. This automation process has helped the customers to book for an appointment and search for the services provided by the hospitals from the comforts of their home. There are various private hospitals available in Muscat, Oman. If a patient would like to compare the services provided by various hospitals, he/she has to browse web-application of each hospital separately and book an appointment. Due to the unavailability of various hospitals information in one web application, patient needs to compare services provided by various hospitals individually and book an appointment which needs considerable time and efforts. In this research paper, we are proposing a prototype system for web-based integrated view of various hospitals where a patient can compare services and seek an appointment with ease. The proposed system also contains the central repository of medical records of patients, which can be useful to track down the medical history of patients. The proposed prototype system facilitates the community in Oman to compare and choose the healthcare services provided by various private hospitals.

\section{RESEARCH METHODOLOGY}

The following research methodology has been adopted in doing this research.

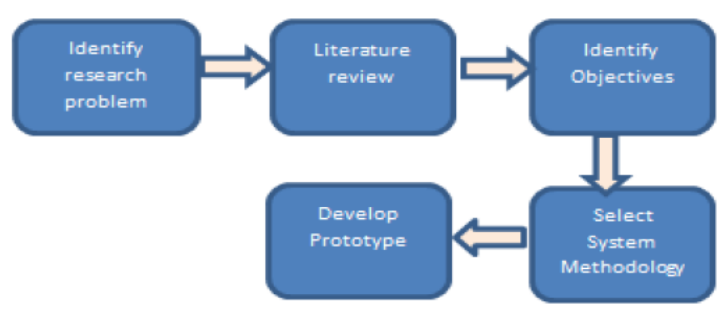

Fig. 1: Research Methodology

\section{REVIEW OF RELATED LITERATURE}

Hospital provides personalized services to individual patients, consists of divergent group of people from various professional [1]. The core objective of a hospital system is to provide quick and efficient services to the community. Computerized hospital management systems provide an automated way of processing the hospital management activities. In the last decade or two, automated hospital management systems have become a necessity as they provide efficient services in improving the healthcare requirements of the society. The development of automated systems related with healthcare will provide in analyzing the health issues, improving operational efficiency of the hospitals [2]. Use of information technology is crucial in patient satisfaction, improving the quality in healthcare sector, and ultimately reducing the costs of providing healthcare services. Some of the private hospitals in Muscat, Oman are providing online facilities through their own web-based applications. Some of the hospitals providing online facilities for patients are Muscat Private Hospital, Starcare Hospital, Burjeel Hospital Oman, Al Hayat International Hospital etc. To gather information from the existing systems the above mentioned hospitals web applications have been referred.

Starcare hospital has a web-based application which provides facility of booking an appointment. It also provides

a. Department of Computing, Middle East College, Muscat, Oman Correspondence: ateeq@mec.edu.om 
information on available services. However, information of doctors related with the services and fee details of services were not available. Muscat Private Hospital has provided a good web interface showing available services, doctors related with the services and appointments, but for their specific hospital only.

\section{A. Research Question}

How to integrate the services provided by various hospitals in a single web-based application and ease the appointment process?

\section{B. Research Objective}

From the existing literature, it is clear that, there is a need for developing a web-based application which can provide integrated services of various hospitals. The proposed research is a work towards developing a prototype for this purpose.

\section{Data Collection}

The data collection has been done mostly using questionnaires. Questionnaires were given to the patient's by visiting various private hospitals. Questionnaires were given to 112 patients at various private hospitals. The responses given by the patients regarding their satisfaction from the existing services is shown in figure 2 . The responses given by the patients showing the need of integrated services for various hospitals in a single web-based application are shown in the figure 3 . In some cases, interviews are conducted with hospital admin staff, doctors and randomly selected patients at various private hospitals in Muscat.

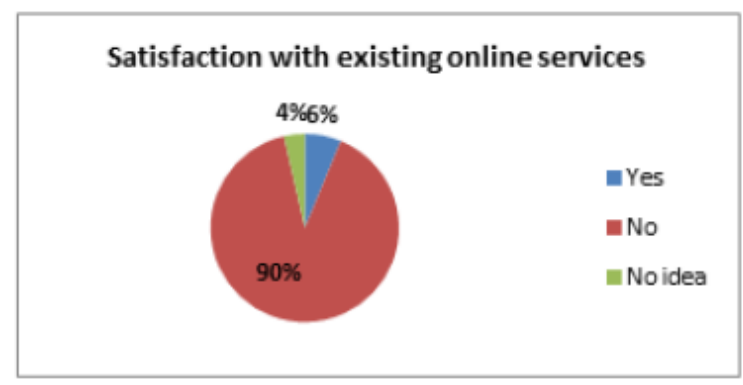

Fig. 2: Patients response for satisfaction with existing services

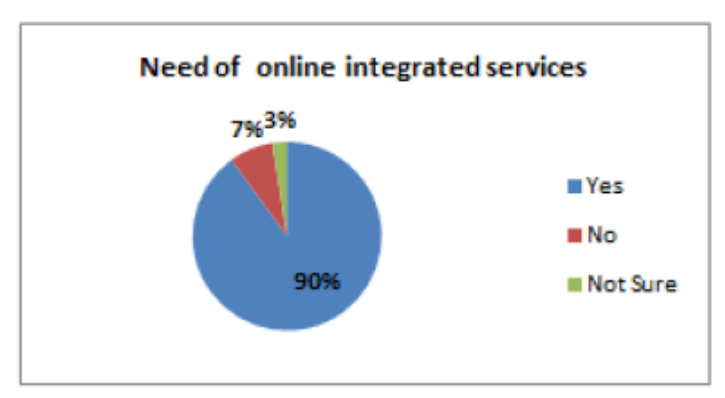

Fig. 3: Patients response for need of integrated services

Requirements have been collected from hospital staff including administration staff and doctors. Patients are also interviewed to know their requirements. Based on the research questions, data has been collected and analyzed to provide better integrated healthcare services.

\section{SYSTEM DEVELOPMENT METHODOLOGY}

Various system development methodologies are thoroughly studied and compared, prototype system development methodology has been chosen for IHMS. As per the chosen methodology, major requirements of the system are gathered. Once the data requirements have been gathered, initial system design has been done. Based on the design, initial prototypes are developed. These prototypes are evaluated through the stakeholders like doctors, administration staff and patients.

The prototype methodology is useful in getting feedback from the users. Based on the review and feedback, changes are done to get the final approved prototypes. The benefit of using this methodology is the end users i.e. hospital administration staff, doctors and patients are involved in the in the development of prototypes resulting in a usable system. In case of other methodologies, users are involved after the system is developed, which can be costly if several changes are suggested at such a later stage of system development. The various stages in the chosen methodology is shown in the figure 4 .

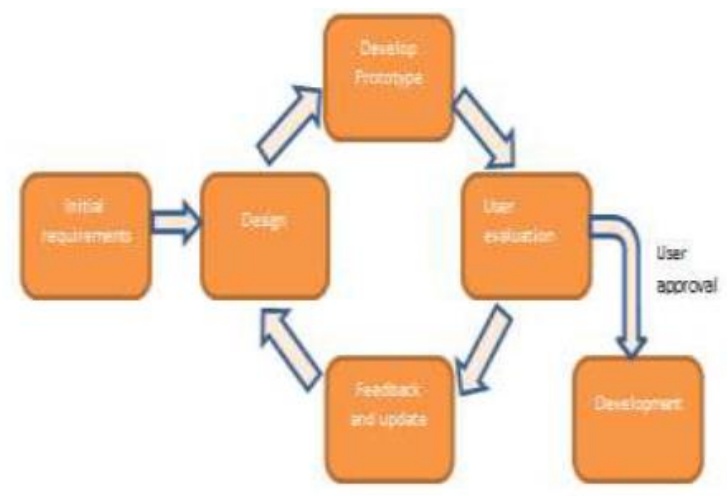

Fig. 4: System development methodology

\section{V.SYSTEM DESIGN}

The integrated hospital information system has various modules or sub-systems such as patient, doctors, administration staff, services provided by the hospitals, comparison of services in terms of consultation fee, patients appointment booking, doctor's prescription for the patient and various reports to track down the medical history of the patient 
and analysis of data. Based on the information gathered in the requirement analysis phase, various designs have been done. The IHMS should provide the facility to store the data in a database. In order to develop an efficient and optimized system, database design has been normalized and the corresponding entity relationship diagram of IHMS is shown in the figure 5. Appropriate relationships between entities have been done with applicable integrity constraints.

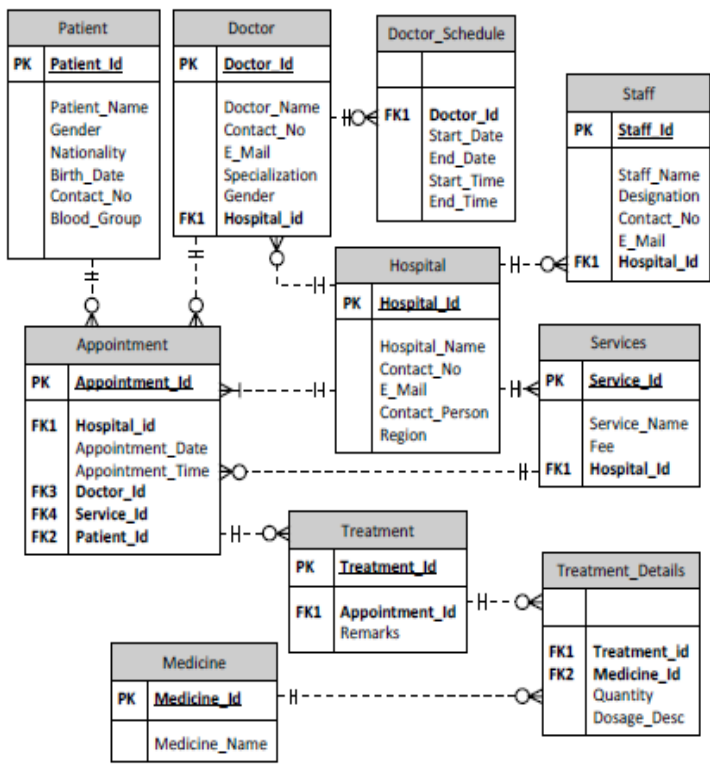

Fig. 5: Entity-relationship diagram

Based upon the chosen methodology for the system development i.e. prototype methodology, during the prototype development phase of IHMS, users are involved. Prototypes have been shown to Doctors, Patients and hospital administration staff for review and feedback. Suggested changes by the users have been applied before reaching the final prototype of the IHMS. The flow of events developed for IHMS web-based application is shown in the figure 6.

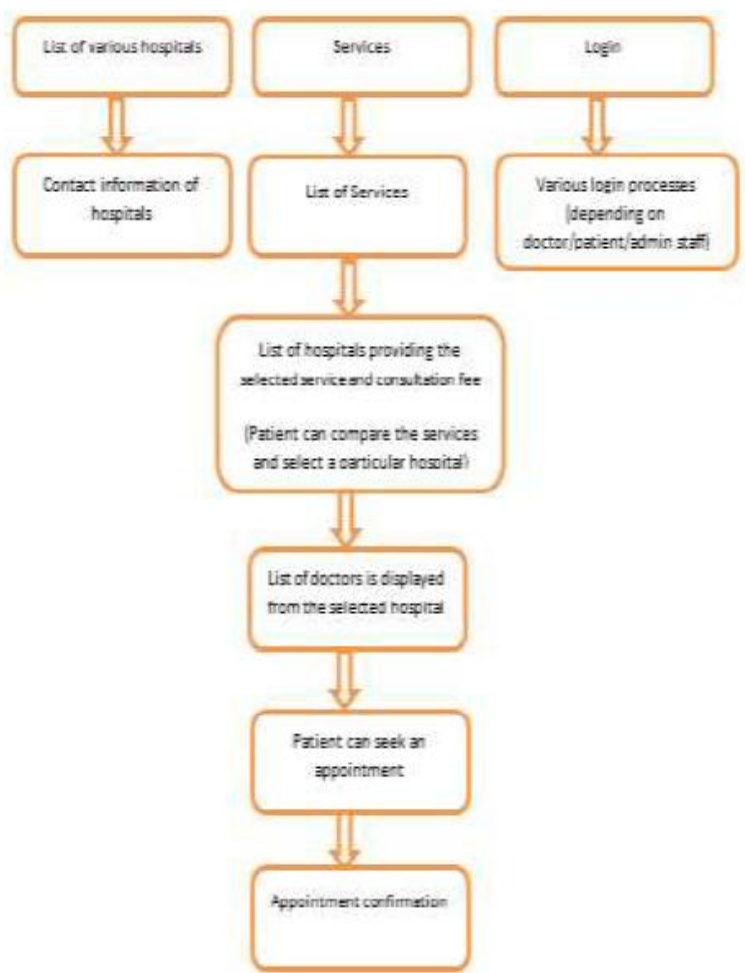

Fig. 6: Process flow for integrated hospitals services

Patient has to initially register in IHMS. The ER diagram shown above has the required attributes of patients. Once registered, patient can seek an appointment by choosing hospital, service and the doctor. Patient appointment process is as shown below.

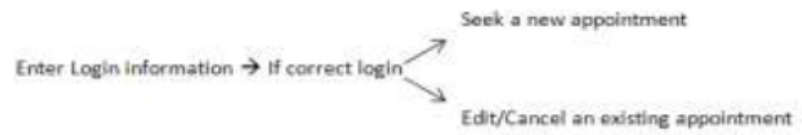

Doctors should be registered in the IHMS and the Doctor process is as shown below:

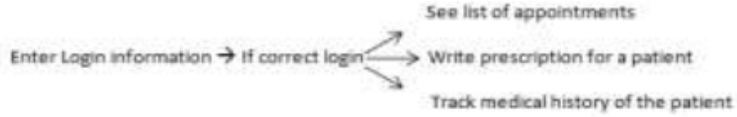

Hospital administration staff process is as shown below:

$$
\text { Enter Login information } \rightarrow \text { If correct login }
$$

\section{RESEARCH RESULT AND PROTOTYPE}

The research has resulted in the development of prototype for the integrated hospital system having the following modules: 


\section{A. User Login}

The prototype of the home page is shown in figure 7. The users of IHMS are doctors, patients, and hospital staff. When a user opens the web application, the home page having list of services, list of hospitals, link for seeking an appointment and a link for login is displayed. Patient must register to book an appointment and track their previous medical records. Doctor and admin staff must also be registered in the system.

\section{B. Hospitals}

List of hospitals shall be displayed from the home page of the IHMS as shown in the figure 7. Users can select any hospital from the list, services offered by the chosen hospital will be displayed. When a user selects any service, list of doctors specialized in the service are displayed along with the consultation fee.

\section{Services}

When a user selects the services list, list of all services should be displayed, as shown in the figure 7. User can select a service, list of hospitals, name of doctors, and consultation fees are displayed

\section{Appointment}

Patient can compare the services provided by various hospitals. Patient has the choice to choose any doctor from various hospitals and book an appointment. Appointment can be edited or cancelled, if needed.

\section{E. Doctors}

Doctors offering services in various hospitals can be Registered in IHMS. Doctors can see the list of appointments, select an appointment and record the treatment details. The recorded treatment details can be useful to track the medical history of patients.

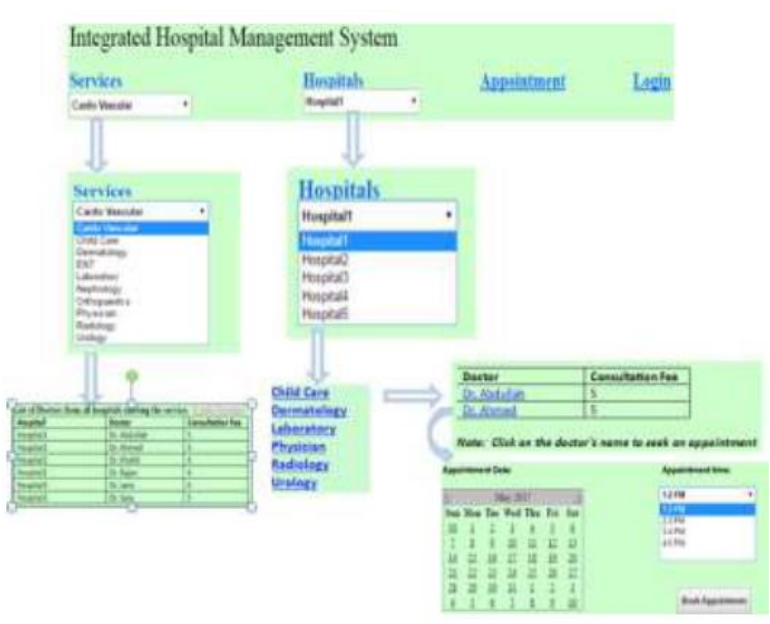

Fig. 7: Prototype for home page, services and appointment

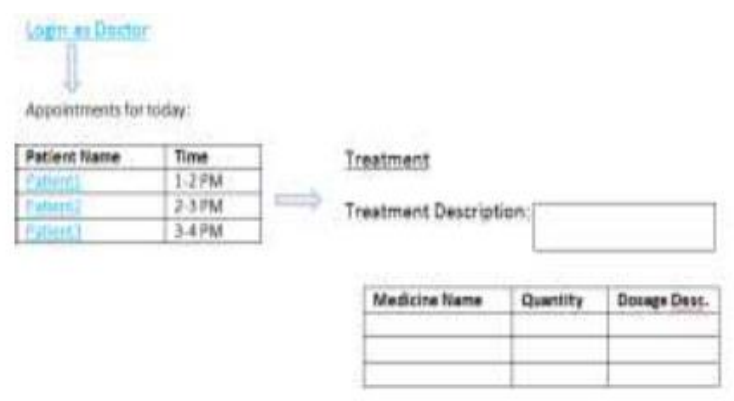

Fig. 8: Prototype for doctor process

\section{F. Hospital Staff}

Hospital staff can be registered in the IHMS. Staff can see the list of appointments, manage hospital's services information, and contact information.

\section{G. Reports}

The integrated system can generate various reports based upon the available doctors, hospitals, services and patient details.

\section{CONCLUSION AND FUTURE WORK}

The prototype of integrated hospital management system provides an easy way for the patients to compare services provided by various private hospitals. Patients can seek an appointment with any doctor from the various hospitals by comparing services and consultation fee. Integrated system reduces the time in comparing the services. Healthcare service is improved as the system provides an efficient and optimized 
way of providing healthcare services to the community in Muscat, Oman. It is recommended to implement the system based on the prototype developed in this research paper for integrating services provided by various private hospitals in a single web application.

\section{References}

[1] A.K.Malhotra, Hospital Management System, Global India Publications, Delhi, 2009.

[2] Olusanya Olamide, Elegbede Adedayo, and Ogunseye Abiodun, "Design and Implementation of Hospital Management System Using Java", IOSR Journal of Mobile Computing \& Application, Volume 2, Issue 1, Apr. 2015.

[3] Farzandipour M, Sadoughi F and Meidani Z, "Hospital Information Systems User Needs Analysis: A Vendor Survey", Journal of Health Informatics in Developing Countries, March 2011.

[4] Ilo S.F, Igbajar Abraham, Acholonu Joyce .C., "Designing A Web Based Hospital Management System For MOUAC Clinic", International Journal of Trend in Research and Development, vol. 2(6), Nov-Dec 2015.

[5] Jeffrey A. Hoffer, V. Ramesh, and Heikki Topi, "Modern Database Management", 10th ed., Prentice Hall, 2011.

[6] A.Silberschatz, H.F.Korth, and S.Sudarshan, "Database System Concepts", 6th ed., Mc Graw Hill, 2011.

[7] K.E. Kendall and J.E. Kendall, "System Analysis and Design", Prentice Hall, 2008.

[8] S.L. Pfleeger and J.M.Atlee, "Software Engineering: Theory and Practice", 4th ed., Pearson Education, 2010.

[9] T.A. Powell, "Web Design: The Complete Reference”, 2nd ed., McGraw- Hill Education, 2002.

[10] Darshana Shah and Aditya Bakshi, "Review on Hospital Management System", International Journal of Research In Science \& Engineering, Volume 1 .

[11] M.L. Despa, "Comparative Study on Software Development Methodologies", Database Systems Journal, vol. 5, March 2014. 